\title{
Thin-layer chromatography of trinitrophenyl derivatives of amino acids in urine and plasma
}

\author{
D. PHILPOTT \\ From the Department of Pathology, General Hospital, Northampton
}

The use of 2,4,6-trinitrobenzene-1-sulphonic acid (TNBS) for the preparation of the trinitrophenyl derivatives of amino acids and peptides was described by Okuyama and Satake (1960) and Satake, Okuyama, Ohashi, and Shinoda (1960). It was observed by Nitecki, Stoltenberg, and Goodman (1967) that mixtures of trinitrophenyl-amino acids could be resolved remarkably well by thin-layer chromatography. They further noted that the preparation of these derivatives presented a number of distinct advantages over that of dinitrophenyl amino acid derivatives prepared with the aid of 1-fluoro-2,4-dinitrobenzene. The TNBS reagent is water soluble, resulting in homogeneous reaction mixtures, and side reactions are largely avoided.

The technique of Nitecki et al (1967) has been applied here, with some modification, to urine and plasma, the amino acid profiles being investigated densitometrically.

\section{Materials}

Analytical or 'special for chromatography' grade reagents were employed when available. The chloroform used contained $2 \% \mathrm{v} / \mathrm{v}$ of ethanol.

Thin-layer chromatography plates, $5 \times 20 \mathrm{~cm}$, and cylindrical jars, $6.5 \mathrm{~cm}$ diameter, approximately $22 \mathrm{~cm}$ high, and with ground glass lids,

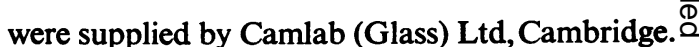

Silica gel $\mathbf{G}^{\mathbf{1}}$ (Kiesel $\mathbf{G}$ nach Stahl) was used. $\overrightarrow{\overrightarrow{0}}$ Distilled water, was added to $30 \mathrm{~g}$ silica gel in 3 a 500-ml conical flask fitted with a rubber bung. The flask was shaken vigorously by hand for 2 min before pouring the contents immediately응 into a Quickfit \& Quartz spreader. This quantity: of slurry was sufficient to coat 20 plates with a layer $0.25 \mathrm{~mm}$ thick. The plates were airi dried for 24 hours before use. No activation’ was employed.

\section{Methods}

As changes occur in urine and plasma con- $N$ stituents in a few hours at room temperature, 0 all specimens were stored at $-20^{\circ} \mathrm{C}$ until ready for processing.

It should be established that the patients under investigation is not receiving drugs, 0 of which metabolites in the urine would formo TNP derivatives. Examples are penicillamine in the urine of patients receiving penicillin, $\mathbb{\mathbb { D }}$ and nitrazepam (Mogadon), which is partlyo excreted in a reduced form, the nitro group being converted to an amino group.

'Anderman \& Co Ltd, Battlebridge House, Tooley Street, London.

Received for publication 11 September 1969. 
1 NEUTRAL AND ACIDIC AMINO ACID DERIVATIVES

\section{Urine}

To $1 \mathrm{ml}$ of specimen in a glass-stoppered centrifuge tube was added $1 \mathrm{ml}$ of water, $1 \mathrm{ml}$ of $4 \%$ sodium bicarbonate solution, and a knife-point (50 mg approximately) of 2,4,6-trinitrobenzene1-sulphuric acid. In the case of very dilute specimens, $2 \mathrm{ml}$ undiluted urine was taken. The mixture was kept for two hours in the dark at $37^{\circ} \mathrm{C}$, cooled, and then acidified with $1 \mathrm{ml}$ $1 \mathrm{~N}$ hydrochloric acid. The trinitrophenyl amino acid derivatives were extracted into two $5 \mathrm{ml}$ portions of ether, and centrifuged briefly to assist separation. The combined extracts were dried over anhydrous sodium sulphate and then evaporated to dryness in a water bath. The residue was cooled and dissolved in $0.1 \mathrm{ml}$ acetone, transferred to a small tube, and stored, well stoppered, in the dark at $-20^{\circ} \mathrm{C}$.

\section{Plasma}

Protein was removed by heat coagulation. To $1 \mathrm{ml}$ of plasma in a small test tube was added $1 \mathrm{ml}$ of $0.05 \mathrm{~N}$ acetic acid. The mixture was heated in a boiling water bath for $3 \mathrm{~min}$, cooled, and centrifuged. The supernatant fluid was decanted into a glass-stoppered centrifuge tube, subsequent processing being as described for urine.

\section{BASIC AMINO ACID DERIVATIVES (URINE AND PLASMA)}

Any residual ether remaining after extraction was pipetted off. Acetone, $0.5 \mathrm{ml}$, was added to the residual fluid and the mixture was saturated with solid ammonium sulphate. After centrifuging, the acetone layer was quantitatively transferred to a small tube and stored at $-20^{\circ} \mathrm{C}$.

\section{CHROMATOGRAPHY}

Aliquots of the acetone solutions derived from 1 ( $10 \mu 1$ of the urine extract and $20 \mu 1$ of the plasma extract) were applied with micropipettes at points $2.5 \mathrm{~cm}$ from the end of a $5 \times 20 \mathrm{~cm}$ silica gelcoated plate to provide spots not exceeding $4 \mathrm{~mm}$ diameter and developed with $30 \mathrm{ml}$ of a freshly prepared 9:1 v/v mixture of chloroform and glacial acetic acid in a cylindrical jar with a ground-glass lid. The solvent front was allowed to advance to a horizontal line marked on the plate $10 \mathrm{~cm}$ distant from the point of application. This required approximately 35 minutes. The developed plate was allowed to dry in the draught of a fume cupboard for 10 minutes.

Portions, $20 \mu \mathrm{l}$, of the acetone solutions, derived from 2 (plasma or urine), were similarly chromatographed in a freshly prepared solvent mixture composed of $30 \mathrm{ml} \mathrm{n}$-butanol and $1 \mathrm{ml}$
1N hydrochloride acid. This took approximatel $\stackrel{c}{\complement}$ 120 minutes.

Whereas all trinitrophenyl amino acid de-D rivatives were visible initially as yellow spots of the plate, darkening was observed in varying. degree on exposure to light and air, particularly: in the case of the sulphur-containing amino acids. The procedures were therefore executer throughout in subdued light and densitometris was undertaken without delay after drying the plates.

\section{DENSITOMETRY}

Recording of the developed plates was carried out with a Vitatron densitometer employing an $O B 1$ Chance blue filter and $3 \times 0.2 \mathrm{~mm}$ slito A pinpoint size hole made in the gel at the poini of application of the extract was recorded in the tracing as a narrow rectangular troughw as was also the line marking the solvent frontr, thus enabling exact measurement of $R_{f}$ values? When one or more derivatives were found present in excess amounts more accurate values wer⿸ obtained by repeating the chromatogram witk smaller aliquots of the acetone solution.

\section{Results}

The excellent separation of mixtures of trinitro phenyl derivatives of amino acids obtained bo Nitecki et al (1967) by thin-layer chromatograph. with pure solutions was repeated when applieg to urine and plasma. Nine to 10 clearly define spots of trinitrophenyl derivatives of neutral. and acidic amino acids were normally obtaine $\bar{c}$ and were recorded as well defined peaks oin the densitometer tracings. They were invariably. preceded on the plate in both urine and plasme chromatograms by the crescent-shaped spow of picramide. This showed intense yellow fluorescence under ultraviolet light at $350 \mathrm{~m} \mu$ Its presence has been attributed to the action of ammonia, derived from glutamine, on the TNBS reagent. Urea, too, was found here to be "hydroo lysed' to some extent to produce picramide iff similar fashion. Fortuitously, the picramide spod formed a useful marker to which the trinitroo phenyl amino acid derivatives could be referred They have been designated $R_{p}$ values anf were adopted in preference to $\mathbf{R}_{\mathbf{f}}$ values due to their greater reproducibility. With care in the preparation of the plates $\left(R_{p} \times 100\right)$ values (Table I) were found to be reproducible withi \pm 2 . Typical chromatograms of trinitropheny $\vec{\rho}$ derivatives of neutral and acidic amino acids derived from urine and plasma are illustrated ip Figures 1-3. The small amount of picric acie produced and extracted remained at or near the origin.

Chromatography of the ether-insoluble basic 


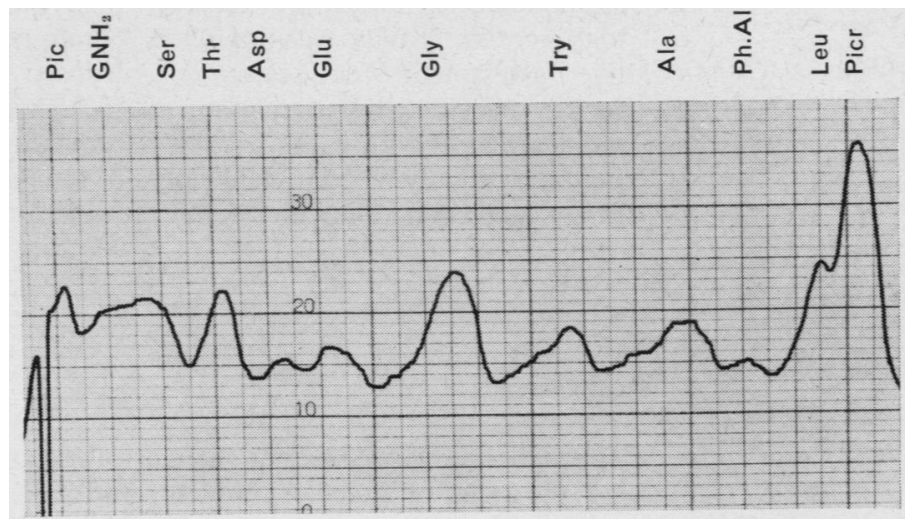

Fig. 1 Urine, adult, showing Pic, $\mathrm{GNH}_{2}, \mathrm{Ser}, \mathrm{Thr}$, Asp, Glu, Gly, Try, Ala, Ph.Al, Leu, Picr.

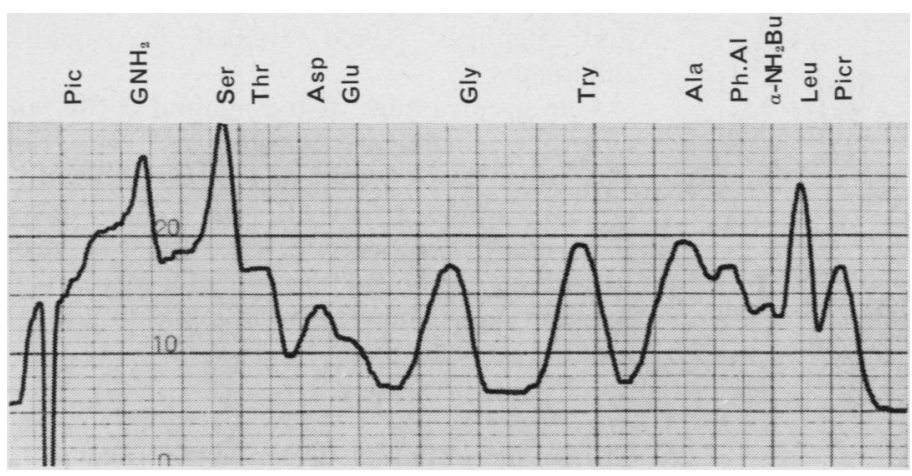

Fig. 2 Plasma (child, aged 2 yr, epileptic), showing Pic, GNH $\mathrm{H}_{2}$, Ser, Thr, Asp, Glu, Gly, Try, Ala, Ph.Al, a-NH $\mathrm{H}_{2} \mathrm{Bu}, \mathrm{Leu}, \mathrm{Picr}$.

Key to Figures 1 and 2

$a-$ Aminobutyric acid $=a-\mathrm{NH}_{2} \mathrm{Bu}$; alanine = Ala; aspartic acid = Asp; glutamic acid = Glu; glutamine = $\mathrm{GNH}_{2} ;$ glycine = Gly; histidine = Hist; 3-methylhistidine = 3-meth-hist; homocystine = homocyst, leucine = Leu; methionine = Met; phenylalanine; Ph.Al; picric acid = Pic; picramide $=$ Picr.

amino acid TNP derivatives presented some difficulties. The salting-out procedure adopted here proved more satisfactory than the direct spotting of the acid reaction mixtures onto the plates proposed by the original authors. The acid-butanol solvent mixture finally adopted was the best of a wide range of solvent mixtures investigated. Figure 4 illustrates a typical chromatogram of the trinitrophenyl derivatives of basic amino acids in a normal urine. $R_{\mathfrak{f}}$ values are listed in Table II.

In the case of diamino acids, where monoand bis-substitution is possible, ether-soluble

\begin{tabular}{|c|c|c|}
\hline Amino Acid & $R_{p} \times 1$ & ${ }^{\infty} \Omega$ \\
\hline Citrulline & 5 & \\
\hline Glutamine & 8 & لరి \\
\hline Cystine & 9,39 & 豈 \\
\hline Asparagine & 10 & 으 \\
\hline Cystathionine & 14,25 & \\
\hline Serine & 16 & $\overrightarrow{\bar{F}}$ \\
\hline Threonine & 21 & $\underline{s}$ \\
\hline Aspartic acid & & $\tau$ \\
\hline Homocystine & 33,61 & $\frac{\bar{\sigma}}{\sigma}$ \\
\hline Glutamic acid & 35 & 을. \\
\hline Tyrosine & 38 & $\underline{0}$ \\
\hline Cysteine & 47 & a \\
\hline Glycine & 52 & 5 \\
\hline Homocysteine & 62 & 8 \\
\hline Ornithine & 63 & \\
\hline Tryptophan & 65 & $\overrightarrow{0}$ \\
\hline Alanine & 78 & \\
\hline Lysine & 82 & $\vec{c}$ \\
\hline Methionine & 82 & $\omega$ \\
\hline Phenylalanine & 86 & $\frac{0}{0}$ \\
\hline B-Alanine & 89 & $\frac{9}{0}$ \\
\hline$\alpha$-Aminobutyric acid & $\begin{array}{l}90 \\
92\end{array}$ & iు \\
\hline $\begin{array}{l}\text { B-Aminoisobutyric acid } \\
\text { Leucine }\end{array}$ & $\begin{array}{l}92 \\
94\end{array}$ & $A$ \\
\hline Isoleucine & 94 & $\ddot{\omega}$ \\
\hline Valine & 97 & $\vec{G}$ \\
\hline
\end{tabular}

Kynurenine $\quad 9,75,850$

Carnosine

Penicillamine

85

73, 89

Table I Derivatives of neutral and acidic amino acids

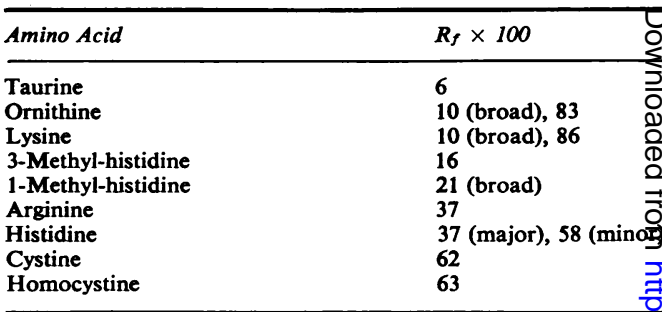

Table II Derivatives of basic amino acids

and ether-insoluble derivatives may be formed. Corresponding reference values are listed in the tables.

Quantitative determination of fluid amino acid content by integration of the densitometer recordings was not undertaken, as the amirm acids were found not to react uniformly wif the TNBS reagent. It was noted, however, that on acidification of the reaction mixture befoze ether extraction, fluids of normal amino acsit content remained clear, or at most exhibited a slight haziness. Formation of a precipita at this stage would indicate the presence of an 


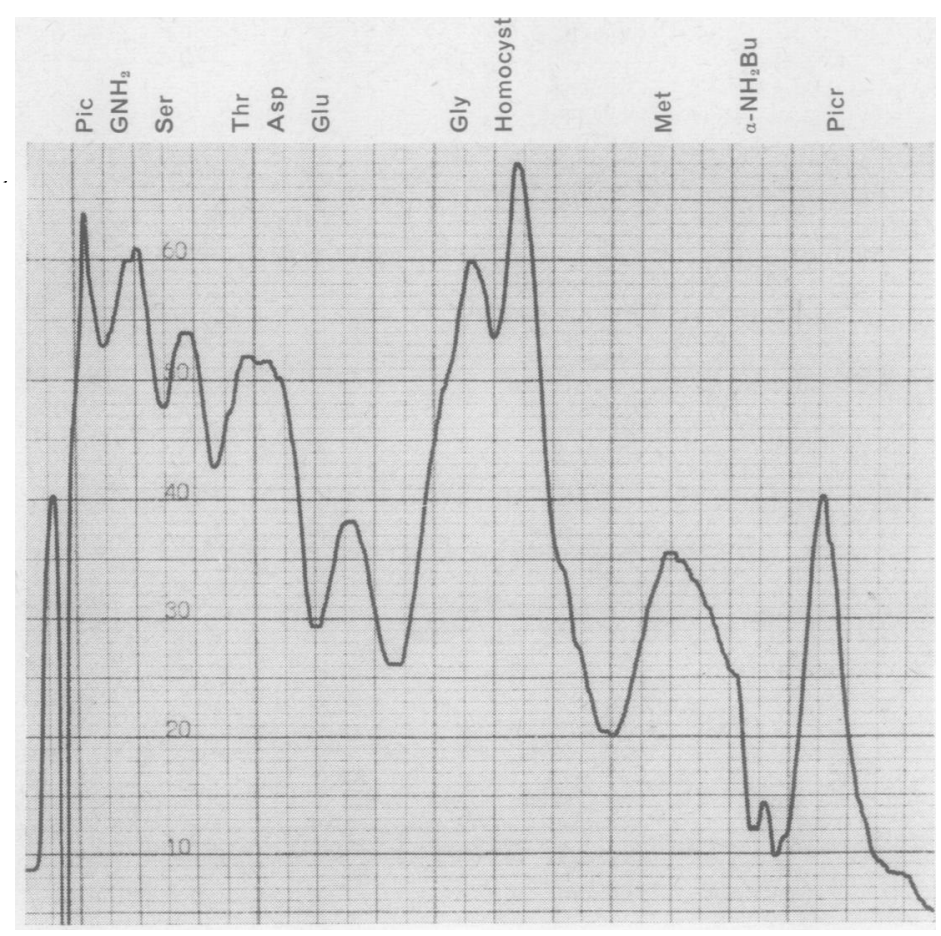

Fig. 3 Urine from a case of homocystinuria in a 11-year-old boy showing Pic, $\mathrm{GNH}_{2}, \mathrm{Ser}, \mathrm{Thr}, \mathrm{Asp}$, Glu, Gly, Homocyst, Met, a- $\mathrm{NH}_{2} \mathrm{Bu}$, Picr.

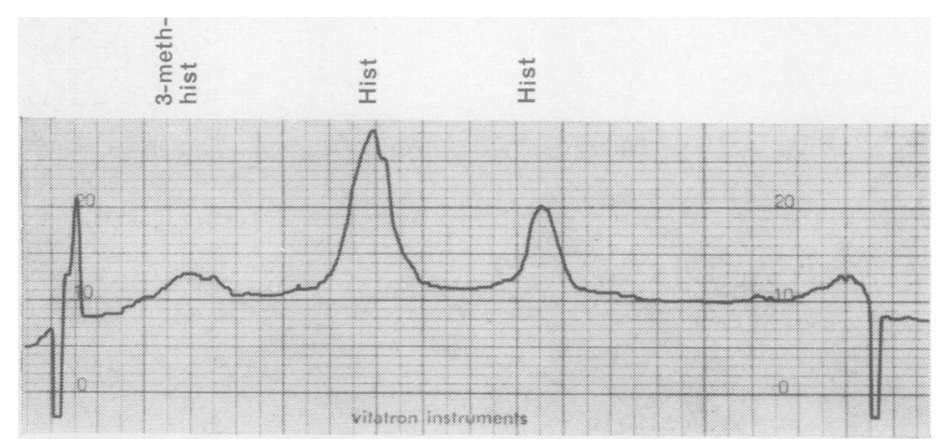

Fig. 4 Urine, adult, showing basic amino acids 3-meth-hist, Hist (two peaks).

Key to Figures 3 and 4 $a$-Aminobutyric acid $=\alpha-\mathrm{NH}_{2} \mathrm{Bu}$; alanine $=$ Ala; aspartic acid = Asp; glutamic acid = Glu; glutamine; $\mathrm{GNH}_{2} ;$ glycine = Gly; histidine =Hist; 3-methylhistidine = 3-meth-hist , homocystine $=$ homocyst $=$ leucine =Leu; methionine = Met; phenylalane = Ph.Al; picric acid = Pic; picramide $=$ Picr. aminoaciduria, unless a specimen of urine of high specific gravity was involved. Semiquantitive assessment for screening purposes wast further provided by comparison of the densito meter tracings with those obtained from norma fluids. Normally in urine the heights of the peaksrarely exceeded that given by the picramides? spot.

\section{Conclusions}

The technique described has the merit for screen- $\overrightarrow{0}$ ing purposes of speed, simplicity, and, for the $\vec{\omega}$ most part, excellent chromatographic resolution 9 The use of heat coagulation for plasma protein precipitation has the advantage of being rapidu but is likely to produce artefacts. However ${ }_{i}^{\omega}$ comparison of the results with those obtainedu using the solvent extraction technique of Naftaline and Stephens (1965) revealed no significang differences.

One disadvantage of the method is the failure of proline and hydroxyproline to form trinitro derivatives since the reagent reacts only with the primary amino groups. Brown (1968), however has recently recorded a derivative of proline formed on prolonged reaction in a more alkaline medium and it may prove possible to adopt the method accordingly.

The assistance of Mr G. B. Dun, medical photographe to the hospital, is gratefully acknowledged.

References

Brown, H. H. (1968). A study of 2,4,6-trinitrobenzene-sulfonic acid for automated amino acid chromatography. Clin... Chem., 14, 967-978.

Naftalin, L., and Stephens, A. (1965). A method for the des termination of free plasma amino acids in ultra-micro quantities. Clin. chim. Acta, 12, 365-369.

Nitecki, D. E., and Stoltenberg, I. M., and Goodman, J. W? (1967). Qualitative and quantitative determination of mixtures of amino acids using 2,4,6-trinitrobenzene-sulfonic acid. Analyt. Biochem., 19, 344-350.

Okuyama, T., and Satake, K. (1960). On the preparation anfor properties of 2,4,6-trinitrophenyl amino acids and peptides. J. Biochem. (Tokyo), 47, 454-466.

Satake, K., Okuyama, T., Ohashi, M., and Shinoda, T. (1960) The spectrophotometric determination of amines, amin 60 acids, and peptides with 2,4,6-trinitrobenzene-1-sulfoni acid. J. Biochem. (Tokyo), 47, 654-660, 